Academic Platform Journal of Engineering and Science

\title{
Sinterleme Yöntemiyle Apatit - Wollastonit Cam Seramik Üretimi
}

\author{
${ }^{* 1}$ Mine Kırkbınar, ${ }^{2}$ Erhan İbrahimoğlu, ${ }^{3}$ Fatih Çalışkan, \\ ${ }^{1, S a k a r y a ~ U y g u l a m a l ı ~ B i l i m l e r ~ U ̈ n i v e r s i t e s i, ~ T e k n o l o j i ~ F a k ., ~ M e t a l u r j i ~ v e ~ M a l z e m e ~ M u ̈ h . ~ B o ̈ l u ̈ m u ̈, ~ E s e n t e p e ~ K a m p u ̈ s u ̈, ~}$ \\ Sakarya, Türkiye, mnekrkbnr@hotmail.com \\ ${ }^{2}$ Sakarya Uygulamalı Bilimler Üniversitesi, Teknoloji Fak., Metalurji ve Malzeme Müh. Bölümü, Esentepe Kampüsü, \\ Sakarya, Türkiye, erhanibrahimoglu@ subu.edu.tr \\ ${ }^{3}$ Sakarya Uygulamalı Bilimler Üniversitesi, Teknoloji Fak., Metalurji ve Malzeme Müh. Bölümü, Esentepe Kampüsü, \\ Sakarya, Türkiye, fcaliskan@ @ubu.edu.tr
}

Araștırma Makalesi

Geliş Tarihi: 06.12.2019

Kabul Tarihi: 30.01 .2020

$\ddot{O} z$

Bu çalışmada, apatit - wollastonit cam-seramik üretilmiş ve karakterizasyon çalışmaları gerçekleştirilmiştir. AW cam seramik üretimi için $\mathrm{CaO}, \mathrm{SiO}_{2}, \mathrm{P}_{2} \mathrm{O}_{5}, \mathrm{MgO}, \mathrm{Al}_{2} \mathrm{O}_{3}$ ve $\mathrm{CaF}_{2}$ bileşikleri kullanılmış ve ağırlıç̧a oranları hesaplanarak toz kompozisyonu hazırlanmıştır. Hazırlanan karışım yaklaşık $1400^{\circ} \mathrm{C}$ 'nin üzerinde 1 saat boyunca alümina pota içerinde ergitilmiştir. Camlaşmış ergiyiğin amorf yapısını oda sıcaklığında korumak için aşırı soğuma şartlarında (suya dökülerek) kritik soğuma hızının üzerine çıkılarak soğutulmuştur. Elde edilen frit tozları ögütülüp kalıpta şekillendirilerek peletler üretilmiş ve $1000^{\circ} \mathrm{C}^{\prime}$ nin üzerinde sinterlenerek hem kristalize yapı elde edilmiş hem de istenilen formda bulk malzeme elde edilmiştir. Ürünlerin kimyasal içeriğini belirlemek amacıyla X-1şını floresans spektrometre (XRF) analizi yapılmıştır. Ayrıca numunelerin mikroyapı incelemesi için taramalı elektron mikroskobu (SEM) ve boyutsal değişimlerinin belirlenmesi için dilatometre analizi gerçekleştirilmiştir. Nihai ürünün faz içeriğinin belirlenmesi için X-ışını Kırınım analizi (XRD) gerçekleştirilerek yapıda oluşan kristalin fazlar ve amorf fazlar tespit edilmiştir. Üretimi gerçekleştirilen AW tozlarının ve bulk malzemenin kimyasal içeriklerinin ve mikroyapılarının literatür ve referans ürünlerle uyumlu olduğu ortaya konulmuştur. Yapılan SEM analizi ile mikroyapının çok düşük miktarda poroziteye sahip olduğu tespit edilmiştir.

Anahtar Kelimeler: Bioaktif, cam seramik, apatit-wollastonit, kemik

\section{Apatite - Wollastonite Glass Ceramic Production by Sintering Method}

\author{
*1 Mine Kırkbınar, ${ }^{2}$ Erhan İbrahimoğlu, ${ }^{3}$ Fatih Çalışkan, \\ ${ }^{1}$,Sakarya University of Applied Sciences, Faculty of Technology, Department of Metallugical Engineering, Esentepe Campus, \\ Sakarya, Turkey, mnekrkbnr@hotmail.com \\ ${ }^{2}$ Sakarya University of Applied Sciences, Faculty of Technology, Department of Metallugical Engineering, Esentepe Campus, \\ Sakarya, Turkey, erhanibrahimoglu@subu.edu.tr \\ ${ }^{3}$ Sakarya University of Applied Sciences, Faculty of Technology, Department of Metallugical Engineering, Esentepe Campus, \\ Sakarya, Turkey, fcaliskan@subu.edu.tr
}

\begin{abstract}
In this study Apatite - wollastonite glass - ceramic production was made and characterization studies were carried out. For the production of A-W glass ceramics, $\mathrm{CaO}, \mathrm{SiO}_{2}, \mathrm{P}_{2} \mathrm{O}_{5}, \mathrm{MgO}, \mathrm{Al}_{2} \mathrm{O}_{3}$ and $\mathrm{CaF}_{2}$ compounds were used and powder composition was prepared by calculating the weight ratios. The mixture was melted in an alumina crucible for 1 hour at a temperature above $1400^{\circ} \mathrm{C}$. To maintain the amorphous structure of the glass melt at room temperature, it was cooled over critical cooling rate by pouring into water. The resulting frit powders were ball milled and pressed into a steel die to produce pellets. After all, the pellets were sintered above $1000^{\circ} \mathrm{C}$ to obtain a stiff bulk material with crystalline structure as desired. X-ray fluorescence spectrometry (XRF) analysis was performed to determine the chemical composition of the product. In addition, scanning electron microscopy (SEM) was used for the microstructure analysis of the samples and dilatometer analysis was carried out to find dimensional expansion or shrinkage value. To detect the phase content of the final product, X-ray diffraction analysis (XRD) was performed to determine the main phases and secondary phases formed in the structure. The final bulk materials had the chemical composition and microstructure of A-W when compared with previous works (reference products). SEM analysis revealed that the microstructure had very low porosity level.
\end{abstract}

*Sorumlu Yazar: Sakarya Uygulamalı Bilimler Üniversitesi, Teknoloji Fak., Metalurji ve Malzeme Müh. Bölümü, Esentepe Kampüsü, Sakarya, Türkiye, mnekrkbnr@hotmail.com, 05068232524 
Keywords: Bioactivity, glass ceramic, apatite wollastonite, cortical bone

\section{GİRIȘ}

Camlar, kristal düzeni olmayan ve düzensiz yapı sergileyen amorf katılar olarak tanımlanmaktadırlar [1].Biyoaktif camlar ise ilk olarak Larry Hench tarafindan ticari ismi "Bioglass ${ }^{\circledR}$ 45S5" olarak adlandırılmıştır [2].

Biyoaktif camlar, yüksek biyouyumlulukları ve biyoaktiviteleri nedeniyle klinik uygulamalar için oldukça iyi malzemelerdir. Biyoaktif camlar ve ayrica hidroksiapatit (HA) ve trikalsiyum fosfat (TCP) gibi bazı kristalli seramikler içerisinde kemiğin gelişimine izin vermekte ve kemiğe sıkı bir şekilde bağlanmaktadır [3].

Biyoaktif camların kusur bölgesine yerleştirilmesinden sonra cam yüzeyi ve çevresindeki biyolojik sıvı arasında iyon değiştirme reaksiyonları gerçekleşmekte ve implant yüzeyi üzerinde kemik benzeri bir apatit tabakasının oluşmasına yol açmaktadır. Bu durum da kemikm ile implant malzemesi arasında bağ oluşmasını sağlamaktadır [4].

İyi bir biyo uyumluluk göstermesine rağmen, biyoaktif camların ve seramiklerin en büyük handikapı düşük darbe dayanımı ve kırılma tokluklarıdır. Bu özellikler seramik olmasının gerektirdiği karakteristik bir özelliktir. Bununla birlikte, bu özelliklerinin geliştirilmesi amacıyla kompozit yapıda üretilmesi için polimerler veya farklı katkılar ve fazlarla kombinasyon gibi yeni stratejilerin geliştirilmesi bu dezavantajların kısmen üstesinden gelinmesine izin vermektedir. Tablo 1'de farklı biyomalzemelere ait mekanik değerler verilmiştir. [5]

Tablo 1. Bazı biyoseramiklerin özellikleri

\begin{tabular}{|c|c|c|c|c|}
\hline Malzeme & $\begin{array}{c}\text { Basma } \\
\text { Mukavem } \\
\text { eti (MPa) }\end{array}$ & $\begin{array}{c}\text { Kirılma } \\
\text { Tokluğu } \\
\left(\mathrm{MPa} \cdot \mathrm{m}^{1 / 2}\right)\end{array}$ & $\begin{array}{c}\text { Ĕgme } \\
\text { Mukave } \\
\text { meti } \\
(\mathrm{MPa})\end{array}$ & $\begin{array}{c}\text { Vickers } \\
\text { Sertliği } \\
(\mathrm{Hv})\end{array}$ \\
\hline HA & $100-150$ & $0,8-1,2$ & $60-120$ & $90-140$ \\
\hline $\begin{array}{c}\text { Bioglass } \\
\text { ( 45S5 }\end{array}$ & - & 0,6 & 40 & - \\
\hline $\begin{array}{c}\text { Cerabone } \\
\text { AW }\end{array}$ & 1080 & 2 & 215 & 680 \\
\hline $\begin{array}{c}\text { Cortical } \\
\text { Bone }\end{array}$ & $100-135$ & $2-12$ & $50-150$ & $60-75$ \\
\hline
\end{tabular}

$\mathrm{Bu}$ özelliklerinin yanı sıra, kompozit olarak üretilmeye çalışılan bu biyomalzemelerin, farklı katkılar ve oluşturulmak istenen fazlar ile biyoaktivitesinin azaltılıp azaltılmadığının hala endişe konusudur. Yani bu katkı ve fazların mekanik özellikleri geliştirirken biyouyumluluğu nasıl etkilediği çözüme kavuşturulması gereken bir başka konudur. [6]. Biyoaktif seramikler arasında, apatit wollastonit optimum bileşimi Kokubo ve arkadaşları tarafindan geliştirilmiş $\mathrm{CaO}, \mathrm{SiO}_{2}, \mathrm{P}_{2} \mathrm{O}_{5}, \mathrm{MgO}, \mathrm{CaF}_{2}$ bileşiğidir [7].

1980'lerde Kokubo tarafından geliştirilen apatit wollastonit cam seramik, diğer cam ve cam seramiklere kıyasla yüksek mekanik mukavemet göstermektedir. Böyle bir yüksek mekanik mukavemet apatite ek olarak wollastonitin çökelmesinden dolayı nispeten yüksek kırılma tokluğuna bağlanmaktadır [8].

Ayrica, apatit wollastonit cam-seramiklerinin en biyoaktif malzemelerden biri olduğu ve apatit wollastonit cam seramiğin biyoaktivite endeksinin, yoğun sinter hidroksiapatitinkinden biraz daha yüksek olduğu literatürde bildirilmiştir. Gerçekte apatit wollastonit cam seramiğin biyoaktivite endeksi 3.2, hidroksiapatitin biyoaktivite endeksi ise 3 'tür. Bu veriler, apatit wollastonit cam seramiğin daha biyoaktif olduğunun ve hidroksiapatit ile karşılaştırıldığında daha kısa sürede kemik ile bağ yaptığı anlamına gelmektedir $[9,10]$

Bu çalışmada, insan vücuduna uyumlu bir yapı olan apatit fazını içeren bir cam seramik yapı elde edilmesi hedeflenmektedir. Wollastonit cam tozunun kontrollü kristalizasyonu ve isıl işlemler sonunda bulk formda AW cam seramik ürünler elde edilecektir. Ürünlerin toz boyut analizi, XRF analizi, XRD analizi ve SEM incelemesi ile karakterizasyonu gerçekleştirilerek hedeflenen yapıya kavuşulma durumu ortaya konulacaktır.

\section{MATERYAL VE METOT}

A-W üretiminde hammadde olarak \%99 saflıkta (Alfa Aesar, $\mathrm{ABD}$ ) olan $\mathrm{CaO}, \mathrm{SiO}_{2}, \mathrm{P}_{2} \mathrm{O}_{5}, \mathrm{MgO}, \mathrm{Al}_{2} \mathrm{O}_{3}$ ve $\mathrm{CaF}_{2}$ bileşikleri kullanılmıştır. Üretim iki aşamada gerçekleştirilmiştir.İlk aşamada frit üretilmiş ikinci aşamada ise bulk malzeme üretilerek karakteriz edilmiştir.

\subsection{AW Toz Üretimi}

Elimizdeki hammaddelerin $\left(\mathrm{CaO}, \mathrm{SiO}_{2}, \mathrm{P}_{2} \mathrm{O}_{5}, \mathrm{MgO}, \mathrm{Al}_{2} \mathrm{O}_{3}\right.$ ve $\mathrm{CaF}_{2}$ ) yüzde oranlarına göre tartım hesapları yapılarak karışım hazırlanmıştır [11]. Hazırlanan karışım homojen karıştırıldıktan sonra alümina pota içerisine alınmıştır. Apatit-Wollastonit cam seramiği, Tablo 2'deki gerçek oksidik kompozisyona göre hazırlanmıştır.

Tablo 2. A-W referans malzemenin kompozisyonu.

\begin{tabular}{ccccccc}
\hline $\begin{array}{c}\text { Kompozisyon } \\
(\%)\end{array}$ & $\mathrm{SiO}_{2}$ & $\mathrm{P}_{2} \mathrm{O}_{5}$ & $\mathrm{CaO}$ & $\mathrm{CaF}_{2}$ & $\mathrm{Al}_{2} \mathrm{O}_{3}$ & $\mathrm{MgO}$ \\
\hline Referans & 33,75 & 13,48 & 48,86 & 0,03 & 1,9 & 1,94 \\
\hline
\end{tabular}

Pota $1380^{\circ} \mathrm{C}$ 'ye ayarlanan firın içerisine yerleştirilmiştir. Fırın sıcaklığ kademeli olarak (her 15 dakikada $5-10^{\circ} \mathrm{C}$ ) arttırılıp yaklaşık $1400^{\circ} \mathrm{C}^{\prime}$ ye çıkılmıştır ve 1 saat ergitme işlemi yapılmıştır. Ergime tüm malzemede homojen olarak gerçekleştiğinde pota firından çıkarılmıştır. Ergiyik, suya dökülerek frit (camsı yapı) haline getirilmiştir. Süzülen numune kurutma firınında kurutulduktan sonra alümina değirmende ögütülmüştür. Daha sonra 1 inç çaplı çelik kalıpta preslenerek peletler elde edilmiştir. Isıl işlem fırınında $500^{\circ} \mathrm{C}$ 'nin üzerinde çekirdekleşme, $1100^{\circ} \mathrm{C}$ 
üzerinde ise sinterleme işlemi gerçekleştirilmiştir. Nihai ürünler fiziksel, kimyasal ve termal analizlerle incelenmiştir.

\section{BULGULAR VE TARTIŞMA}

Karakterizasyon için üretilen toz şeklindeki AW numuneleri kullanılmıştır.

\subsection{X-ışını Floresans Spektrometresi (XRF) Analizi}

Üretilen malzemenin ilk olarak X ışını kırınımı ile içerisinde bulunan oksitler ve bulunan miktarları karakterize edilmiştir. Literatürde çalışmalarında AW kompozisyonu ile üretilen numunelerin toz halde yapılan XRF sonuçları karşılaştırılmıştır. Tablo 3'de verilen XRF sonuçları incelendiğinde orijinal değerlerle karşılaştırıldığında yakın sonuçlar elde edilmiştir. AW tozunun $\mathrm{CaO}, \mathrm{SiO}_{2}$ ve $\mathrm{P}_{2} \mathrm{O}_{5}$ temel bileşenlerdir. $\mathrm{X}$ 1şını kırınım (XRF) analizi için üretilen numune hazırlama aşamasında $9 \mathrm{gr} \mathrm{A}-\mathrm{W}$ tozu ile 1 gr wax bağlayıcı kullanılmıştır.

Tablo 3. A-W referans kompozisyonu ile üretilen malzemenin kompozisyonu

\begin{tabular}{ccccccc}
\hline $\begin{array}{c}\text { Kompozisyon } \\
(\%)\end{array}$ & $\mathbf{C a O}^{*}$ & $\mathrm{SiO}_{2}$ & $\mathbf{P}_{2} \mathrm{O}_{5}$ & $\mathbf{A l}_{2} \mathrm{O}_{3}$ & $\mathrm{MgO}$ & $\mathrm{CaF}_{2}$ \\
\hline Referans & 48,86 & 33,75 & 13,48 & 1,9 & 1,94 & 0,03 \\
XRF sonucu & 48,44 & 33,45 & 13,67 & 2,00 & 1,93 & 0,06
\end{tabular}

\subsection{Tane Boyut Analizi}

A-W tozuna ait grafik incelendiğinde öğütülen tozların \%90'1 36 $\mu$ m'nin altındadır. \%50'si ise $8 \mu \mathrm{m}$ 'den küçüktür. Eğriden de görüleceği üzere toz boyut dağılımı 2 noktada pik yaparak bimodal dağılım göstermiştir. İki noktadaki toz boyut yoğunlaşması daha uzun süre öğütülmesi durumunda tozun dominant şekilde mikron altı seviyeye inebileceğini göstermektedir. Ancak bu çalışma kapsamında toz boyutu yeterli görülmektedir. Likitvanichkul ve ark. yapmış olduğu çalışmada sinterleme için ögütülen $\mathrm{A}-\mathrm{W}$ toz boyutunun 45 mikron altı seviyede olup bu çalışmada üretilen toz spesifikasyonlarıyla uyumlu olduğu görülmüştür [12]. Tozun spesifik yüzey alanı ise; $1.99 \mathrm{~m}^{2}$ /g'dır.

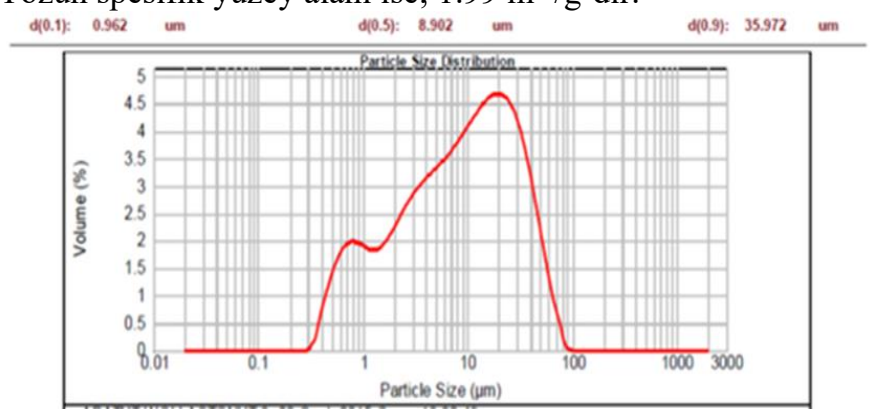

Şekil 1. AW tozlarına ait tane boyut analiz sonuçları. 3.3. XRD Sonuçları
Apatit wollastonite ait XRD paternleri iki farklı numune için de incelenmiştir. Bunlardan ilki üretimi tamamlandıktan sonra toz haline getirilmiş cam AW numunesi içindir. Diğeri ise Şekil 3'te verilen kristalizasyon 1sıl işlemine tabi tutulmuş numuneler içindir. Şekil 2'de cam AW numunesine ait XRD verileri görünmektedir.

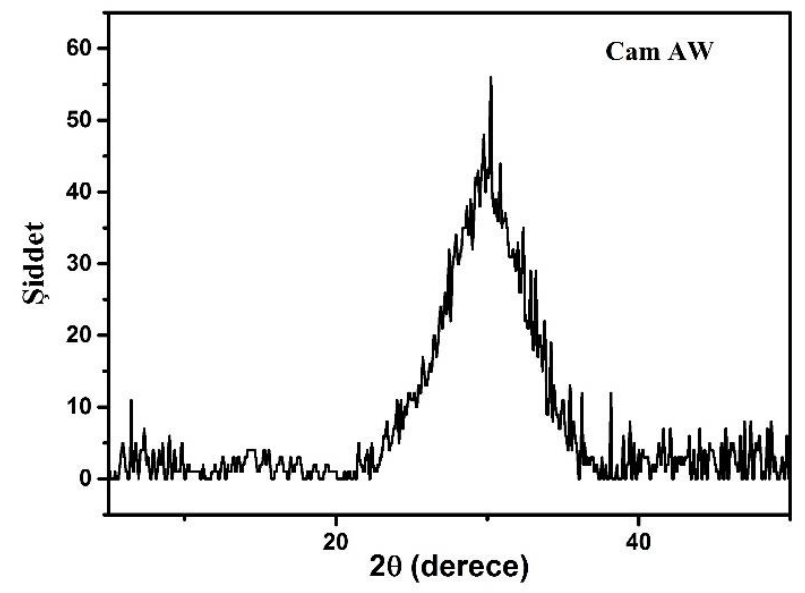

Şekil 2. Cam AW numunelerine ait XRD analiz sonucu Cam AW numunesinin XRD verileri incelendiğinde kristal yapıda bir faz tespiti yapılamamıştır. Bu durum malzemenin \%100 cam olarak üretildiğinin kanıtıdır.

Kristalize numunelere ait XRD verileri ise Şekil 3'te verilmiştir. Şekil 3 incelendiğinde florapatit, wollastonit ve diopsit fazları elde edildiği görülmüştür. Elde edilen pikler literatür ile kıyaslandığında cam ve kristalin AW tozları başarılı bir şekilde sentezlenmiştir. AW cam seramiğinin yap1s1 \%28 kalıntı cam, \%38 apatit $\left[\mathrm{Ca}_{10}\left(\mathrm{PO}_{4}\right)_{6}\left(\mathrm{O}, \mathrm{F}_{2}\right)\right]$, ve $\% 34$ wollastonit $\left(\mathrm{SiO}_{2} \bullet \mathrm{CaO}\right)$ olarak tanımlanmıştır (XRD grafiği alan hesaplama metoduyla hesaplanmıştır).

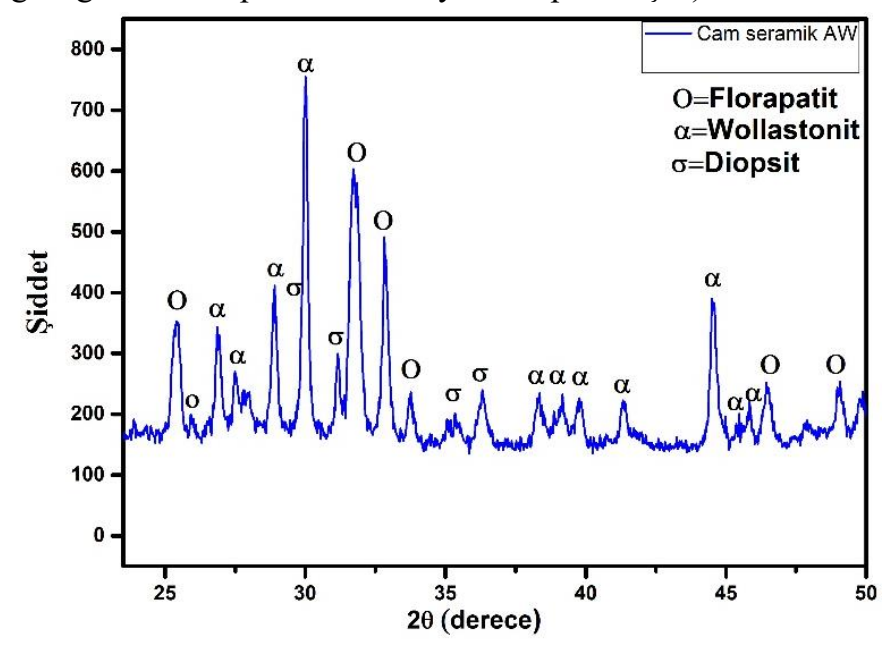

Şekil 3. Kristalize AW tozlarına ait XRD görüntüsü

\subsection{SEM Sonuçları}

Kritik soğuma hızının üzerinde soğutma gerçekleştirerek, kristalizasyon oluşmadan elde edilen numunelerin mikro yapılarını görüntülemek için taramalı elektron mikroskobu görüntüsü alınmıştır. Numuneler metalografik işlemlerle 
hazırlanarak mikroyapi incelemesine uygun hale getirilmiştir. Şekil 4'te A-W biyoaktif cam malzemenin taramalı elektron mikroskobu görüntüsü ve Şekil 5'te EDS sonuçları verilmiştir.
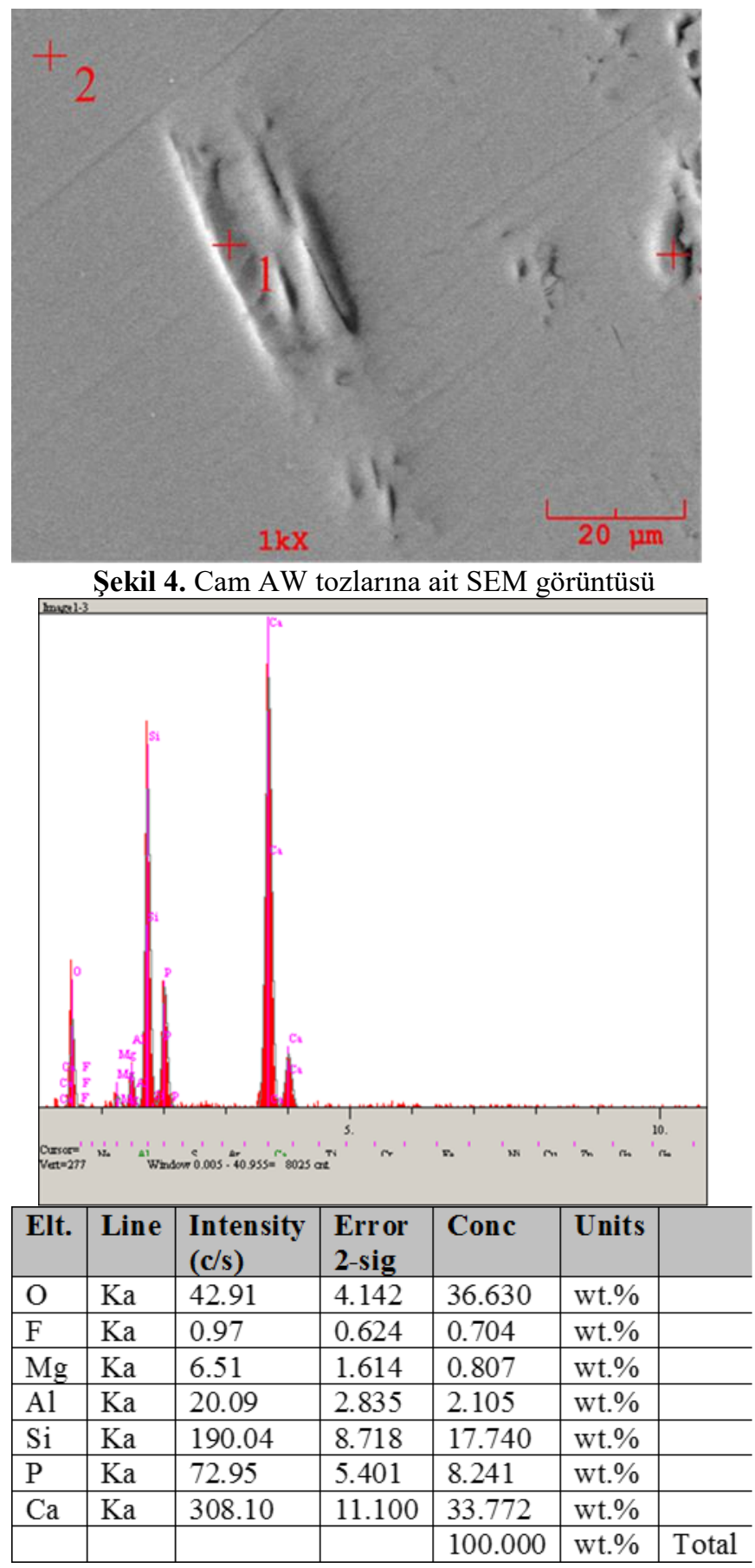

Şekil 5. AW tozlarına ait EDS sonuçları

Görüntü incelendiğinde küçük aşınmaların dışında belirgin bir faz ayrışması ve habbe izlenmemiştir. Literatürde üretilen A-W camları incelendiğinde, genelde cam yapısında prosesin hassas kontrol edilememesinden kaynaklı kontrolsüz kristalizasyon izlenmekte olup ayrıca habbe de gözlenebilmektedir [13]. Ancak mevcut çalışmada prosesin hassas kontrolü sonucu bu tür istenmeyen sonuçlar minimize edildiği Şekil 4'te açıkça görülmektedir. Yüzeydeki izler dökümün yapıldığı grafit kalıp yüzeyindeki pürüzlülükten kaynaklanmaktadır. EDS sonuçlarına bakıldığında, hakim elementlerin oksijen, silisyum, kalsiyum ve fosfor olduğu görülmektedir. Bu durum hakim fazın apatit ve wollastonit olduğuna kanıt oluşturabilir. Bunun yanında bileşimde kullanılan flor, alüminyum, magnezyum elementleri de olması gerektiği gibi yapıda tespit edilmiştir.

\subsection{Dilatometre Sonuçları}

Şekil 6'da ölçümler sonucunda; numunenin termal genleşme katsayısı, hacimsel genleşme, cam geçiş sıcaklığı ve yumuşama noktası tespit edilmiştir. Elde edilen grafikten görüleceği gibi A-W sert bir malzemedir. Normal bir sertliğe sahip malzemeler $700^{\circ} \mathrm{C}$ civarlarında genleşme göstermektedir. Fakat elde edilen grafikten de görüleceği gibi A-W genleşmeye henüz başlamamıştır. Genleşme özelliği yüksek sıcaklıklardaki servis şartlarında çalışması açısından önem arz etmektedir. Ancak vücutta kullanılması hedeflenen durumlarda önem arz etmemektedir.

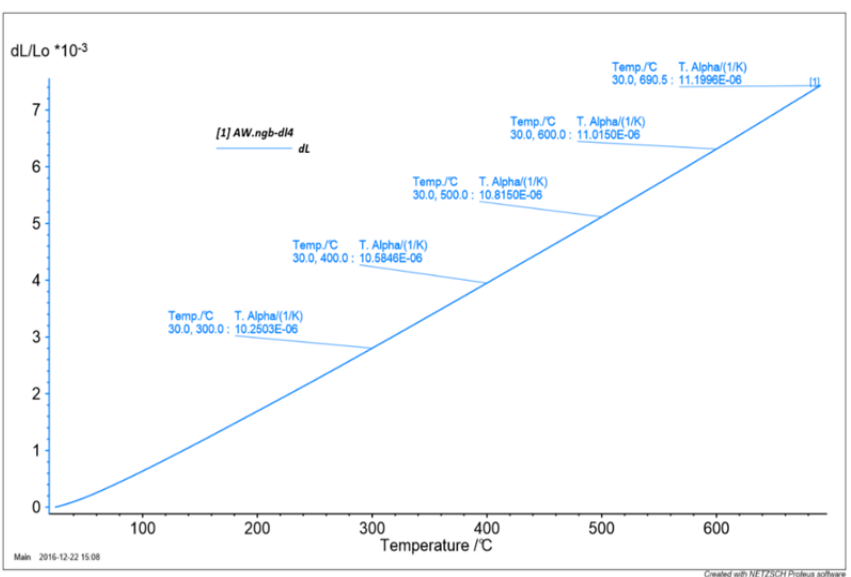

Şekil 6. AW tozlarına ait dilatometre sonucu 3.6. Nem Tayin Cihazı

Elde edilen AW cam seramik tozlarının nem oranlarının tayini toz hazırlama ve pelet elde etme işlemlerinden proses parametrelerini etkileyen bir faktördür. Bu sebepten dolay1 üretilen numunelerin nem miktarları kritik seviyenin altında olmalıdır. Elde edilen veriler incelendiğinde numunenin nem oranı kritik miktarın altındadır. Fazla nem ise sinterleme işleminde ısınma esnasında hızlıca buharlaşmaya çalışarak oluşturacağı buhar basıncı sebebiyle pelet bünyesinin dağılmasına sebep olabilir.

Tablo 4. AW ait nem tayini sonuçları

\begin{tabular}{|c|c|}
\hline Numune Kodu & Nem Oranı (\%) \\
\hline 1 & 0,15 \\
\hline 2 & 0,17 \\
\hline 3 & 0,20 \\
\hline
\end{tabular}

\subsection{Spektrofotometre (Colormeter)}

Numunenin ortodontik aplikasyonlarda kullanılabilme potansiyeli sebebiyle estetik kaygı oluşturmaması için 
spektrofotometre analizi yapılmıştır. İlk olarak üretilen fritler, \%5 kaolen $+30 \mathrm{ml} \mathrm{su}+\% 95$ frit olacak şekilde bir kompozisyonlar tartımı yapılarak hazırlanmış ve bilyalı değirmende 10 dakika süreyle öğütülür. Daha sonra seramik karo yüzeyi, yüzeydeki kirlikleri uzaklaştırmak için ve yüzeyde hidroksil bağları oluşturmak için yüzeye ince bir film halinde nem uygulanır. Yeterli viskoz kıvama getirilen solüsyon özel bir aparat yardımıyla standart numunenin yanına eklenir. Daha sonra seramik firınına şarj edilen seramik karo çifti kademeli olarak isıtılarak isıl çevrim uygulanır. Fırından çıkarılan soğumuş numune spektrofotometre cihazıyla standarttan ölçüm alınır. L,A,B değerleri renkleri ifade etmektedir.

Tablo 5. AW ait Spektrofotometre Sonuçları

\begin{tabular}{|c|c|c|c|c|c|c|c|}
\hline & L & A & B & DL & DA & DB & $\begin{array}{c}\text { DE/ } \\
\text { AB }\end{array}$ \\
\hline Standart & 82,06 & 3,27 & 8,06 & 0,13 & $-0,06$ & $-0,08$ & 0,17 \\
\hline $\begin{array}{c}\text { Deney } \\
\text { Numunesi }\end{array}$ & 81,61 & 3,34 & 8,57 & $-0,32$ & 0,01 & 0,44 & 0,54 \\
\hline
\end{tabular}

Standart numunemizden üretilen numunelerimizin farkı çok düşüktür. Renk verileri olarak standart numuneye yakın değerler elde edilmiştir.

\subsection{F-TIR Sonuçları}

Şekil 7'de verilen AW cam numunenin F-TIR spektrumu incelendiğinde elde edilen pikler ve bulunduğu aralıklar literatürle karşılaştırıldığından standart AW cam numuneleriyle bire bir örtüşmektedir. $900 \mathrm{~cm}^{-1}$ ile $450 \mathrm{~cm}^{-1}$ aralığından içerdiği bağlarla ait karakteristik eğriler vermiştir.

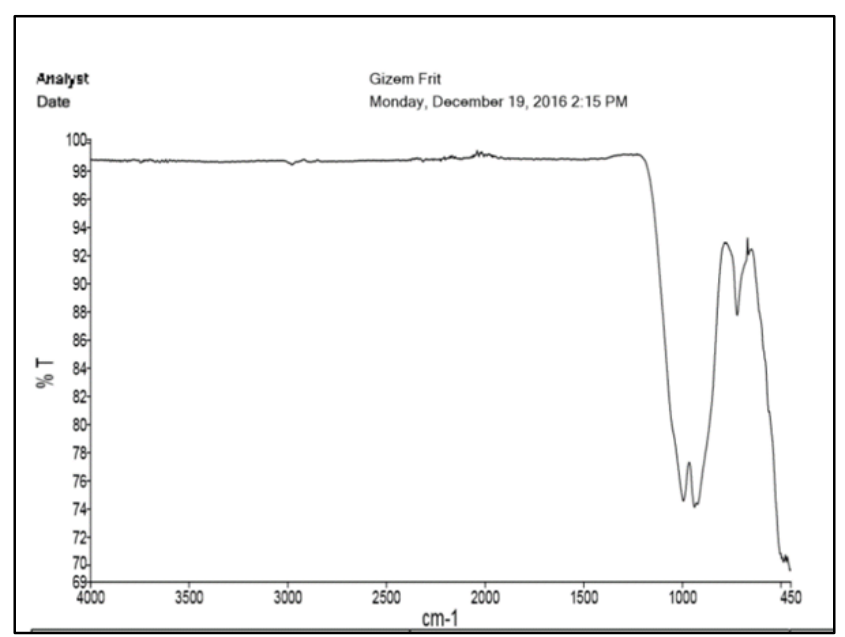

Şekil 7. AW'ye ait F-TIR sonuçları

\section{GENEL SONUÇLAR}

Bu çalışmada cam ergitme metodu kullanılarak literatürde AW cam seramik üretimi için kullanılan kompozisyon ile $\mathrm{AW}$ bileşenlerini içeren amorf yapıda cam ürünlerin üretimi başarılmıştır [14]. AW cam üretimi sırasında prosesin hassas bir şekilde kontrolü oldukça zor olması sebebiyle bu çalışmada monolitik olarak AW camının eldesi oldukça önemlidir. Tamamen cam yapısından başlayarak elde edilen kristalizasyon mikroyapının daha homojen olmasına ve mekanik özelliklerin daha da geliştirilmesini sağlayacaktır. Genellikle kontrolsüz çekirdeklenme ve kristallenme geniş aralıkta tane oluşumlarına ve farklı boyutlarda kristallenmelere sebebp olmaktadır. Sonuç olarak, yapılan analiz sonuçları ele alındığından bu çalışma kapsamında üretilen AW cam seramik malzemenin literatürle uyumlu bir bileşimde ve kontrollü kristalizasyon ile başarılı bir şekilde üretilmiştir.

\section{KAYNAKÇA}

[1]. Williams, D.F., "Definitions in biomaterials", Progress in Biomedical Engineering, Elsevier, Amsterdam, 1987.

[2]. Hench, L.L., West, J.K., "The sol-gel process", Chem. Rev. 90 (1990) 33-72. - Hench, L.L, Wilson, J., "Introduction to Bioceramics", World Scientific, Singapore, 1993.

[3]. [Hench, L.L., "Biomaterials: a forecast for the future", Biomaterials 19, 1419-1423, 1991.

[4]. ALBREKTSSON, T., "Osteoinduction, osteoconduction and osseointegration", Euro. Spine Journal 10 S96-101, 2001.

[5]. KAUR, G., "Mechanical properties of bioactive glasses, ceramics, glass-ceramics and composites: State-of-the-art review and future challenges", Materials Science \& Engineering C 104, 109895, 2019.

[6]. Thompson, I.D., Hench, L.L., "Mechanical properties of bioactive glasses, glass-ceramics and composites", Proceedings of the Institution of Mechanical Engineers, Part H: Journal of Engineering in Medicine, 212: 127, 1998.

[7]. KOKUBO, T., SHIGEMATZU, T., "ApatiteWollastonite Containing Glass Ceramics for Prosthetic Application”, Bull. Inst. Chem. Res., Kyoto Univ., Vol.60, No. 3-4, 1982.

[8]. Cannillo, V., Pierli, F., Sampath, S., Siligardi, C., "Thermal and physical characterisation of apatite/wollastonite bioactive glass-ceramics", Journal of the European Ceramic Society 29 (2009) 611-619.

[9]. Ratner, B. D., Hoffman, A. S., Schoen, F. J. and Lemons, J. E., Biomaterials science. An Introduction to Materials in Medicine. Elsevier Academic Press, 2004.

[10]. R.Tejido-Rastilla, G.Baldi, A.R. Boccaccini', Ag containing polydopamine coating on a melt-derived bioactive glass-ceramic: Effect on surface reactivity' Ceramic İnternationals, 44-13, 2018.

[11]. Timuçin, M. Öztürk, A. Korkusuz, F. et al., Apatit Wollastonit Biyoaktif Seramiklerin Üretimi ve Karakterizasyonu, Proje No: 104M400, Ortadoğu Teknik Üniversitesi, Ankara, Mayıs 2008.

[12]. Likitvanichkul and W.C.lacourse Apatite-Wolastonite glass-ceramics, J. of Materials Scienc, 33 - 5901-5904, 1998. [13]. Chawla, K.K., 'Ceramic Matris Composites, Kluwer Academic Publishers', USA, 2003.

[14]. Murugan, K., and Ramakrishna, S., 'Development of Nanocomposites for Bone Grafting Composites Science and Technology', 2385-2406, 2005. 